\title{
Three Dimensional Finite Element Analysis of Gegou Aqueduct During Operation Period
}

\author{
Y.W. Li \\ Bureau of Comprehensive Development Ministry of water \\ resources \\ Beijing, China
}

Y.F. Zhu

2North China University of Water Resources and Electric Power

Zhengzhou, China

\begin{abstract}
The aqueduct is an important hydraulic structures across the river and traffic line network, and is also an important Hydraulic structures of The south to North Water Diversion Project in China. In this paper Gegou aqueduct is taken as the research object. And a three-dimensional finite element model of Gegou aqueduct is established by ANSYS. The deflection and stress of the structure were calculated under different water level such as space level, semi tank level, design level and full aqueduct water level during operation period. The results show that the design is reasonable and satisfy which could be seen as a theoretical foundation for the design of similar projects.
\end{abstract}

Keywords-gegou aqueduct; finite element; deflection, stress

\section{INTRODUCTION}

Distribution of water resources in China is extremely uneven. So inter-basin water transfer project has become an important content of China's water conservancy construction. In this paper, Gegou aqueduct were calculated by the finite element software ANSYS structural static analysis module with the increase in the water level inside the aqueduct during operations, and distribution aqueduct stress and deflection[1-3].

\section{SUMMARY}

Gegou aqueduct is located in Liaoning Province, design discharge is $1.3 \mathrm{~m}^{3} / \mathrm{s}$, longitudinal slope $1 / 650$, total length is $390 \mathrm{~m}$. This aqueduct is a simply supported beam. Aqueduct body is reinforced concrete structure, a U-shaped cross-section, and each section is $10 \mathrm{~m}$ long aqueduct, aqueduct ends of the body resting on reinforced concrete bent.

\section{CALCULATION MODEL}

\section{A. Model Parameters}

The concrete strength grade for aqueduct body of Gegou aqueduct is C30, density is $2500 \mathrm{~kg} / \mathrm{m}^{3}$, the elastic modulus is 30GPa, and Poisson's ratio is 0.1667[4].

\section{B. Finite Element Model}

Selecting SOLID 65 which is a 8 node 3D element to establish the three-dimensional finite element model of Gegou aqueduct. The element size is 0.05 , the number of element is

\author{
Q.Y. Chen \\ North China University of Water Resources and Electric \\ Power \\ Zhengzhou, China \\ W. He \\ North China University of Water Resources and Electric \\ Power \\ Zhengzhou, China
}

31504, and the total number of nodes is 46941[5-6].In the finite element calculation model of high-rise connected structure, $\mathrm{Y}$ direction is height direction, $\mathrm{Z}$ and $\mathrm{X}$ direction is horizontal, which shows in the Fig.1.

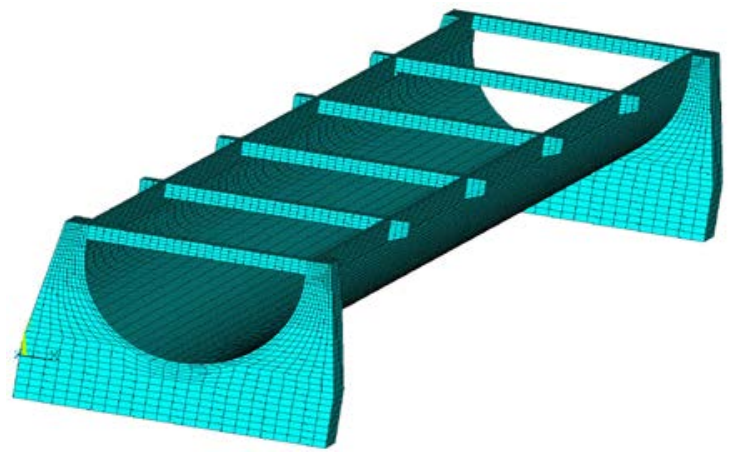

FIGURE I. FINITE ELEMENT CALCULATION MODEL OF GEGOU AQUEDUCT

\section{ANALYSIS OF CALCULATION RESULTS}

The calculation should consider the following conditions in the operation process of Ge Gou aqueduct: The condition 1, aqueduct without water; The condition 2, Half aqueduct water level; The condition 3, Design aqueduct water level; The condition 4, Full aqueduct water level.

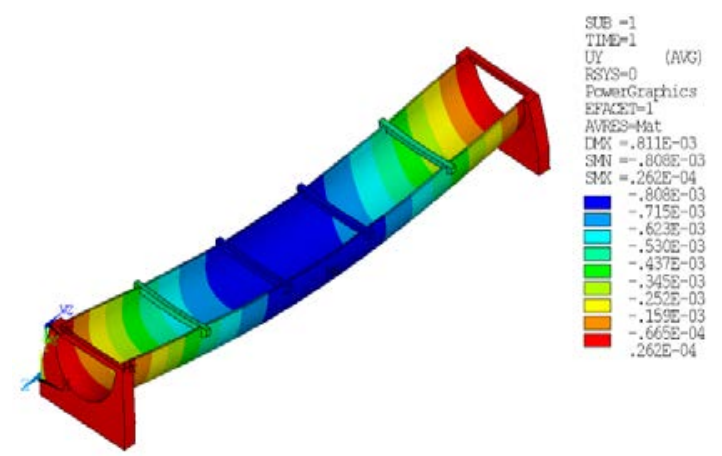

FIGURE II. VERTICAL DISPLACEMENT MAP UNDER CASE1 


$$
\text { 采 }
$$




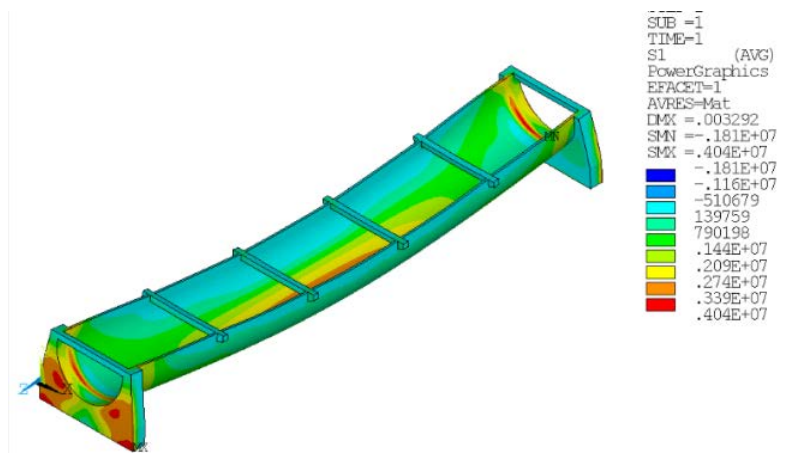

FIGURE IX.

FIRST PRINCIPAL STRESS MAP UNDER CASE 4

Under case 4, we can know that the maximum displacement of aqueduct is $3.292 \mathrm{~mm}$, the maximum displacement in the Vertical direction is $3.28 \mathrm{~mm}$, the first principal stress is 4.04MPa.The calculation results show that the stress of aqueduct body with Full aqueduct water level is smaller than the design value of concrete strength, and also has a smaller displacement, which meet the structural safety specification.

\section{CONCLUSION}

We can know from the results which are calculated according to the above four kinds of condition that the vertical displacement and the first main stress of Gegou aqueduct caused by water load during operation is smaller. One of the most dangerous working condition is full aqueduct water level. While in this condition, the maximum displacement in the Vertical direction is $3.28 \mathrm{~mm}$, the first principal stress is 4.04MPa.So all the four condition of Gegou aqueduct meet the structural safety specification in operational.

\section{ACKNOWLEDGEMENT}

This research was supported by the Science and Technology Program of Zhenzhou (No.20130844); the Foundation of Henan Educational Committee (No.13B130110 and 14A410005).

\section{REFERENCES}

[1] Xiaoqun Li, Yuan Zhang, Haishan Chen. Current situation and trend of development of domestic and foreign aqueduct. The agricultural science and technology and equipment, 12, 2011.

[2] Degang Wang, Yinggang Li. Three-Dimensional Finite Element Static Analyzer the Pressed Drainage Aqueduct. Sci-tech information development \& economy, 19, 2009.

[3] Yulan Sheng, Yahui Duan. Stress and deformation analysis for Yang jiaba aqueduct with three-dimensional finite element method. Water resources and Power, 29, 2011.

[4] The Ministry of water resources of the people's Republic of China, (eds). Code for design of hydraulic concrete structures (SL191-2008). China Water Conservancy and Hydropower Press: Beijing, 2009.

[5] Yu Zhao, Ping Zhao, Shuyao Li. Three-Dimensional Finite Element Analysis of Large Prestressed Concrete Box Flume Structure. Journal of Yangtze River Scientific Research Institute, 16, 1999.

[6] Chongyang Zheng, Hui Peng, Deji Ren. Method of Analyzing Landslide Stability in Critical Condition. Journal of Yangtze River Scientific Research institute, 30, 2013. 